\title{
JOULE HEATING PREANNEALING EFFECT IN THE COERCIVITY FIELD AND MAGNETOSTRICTION CONSTANT OF $\mathrm{Co}_{66} \mathrm{Fe}_{4} \mathrm{Mo}_{2} \mathrm{Si}_{16} \mathrm{~B}_{12}$ ALLOY
}

P. Garcia Tello ${ }^{a}$, J. GonzÁlez ${ }^{b}$, J.M. Blanco ${ }^{a}$ AND R. ŻubereK ${ }^{c}$

${ }^{a}$ Dpto. Fisica Aplicada I, EUITI, San Sebastián, Spain

${ }^{b}$ Dpto. Fisica de Materiales, Facultad de CC Quimicas UPV, San Sebastián, Spain ${ }^{c}$ Institute of Physics, Polish Academy of Sciences

Al. Lotników 32/46, 02-668 Warszawa, Poland

The effect of thermal treatments (by the Joule heating and conventional annealing) on the coercivity and saturation magnetostriction constant in the amorphous and nanocrystalline $\mathrm{Co}_{66} \mathrm{Fe}_{4} \mathrm{Mo}_{2} \mathrm{Si}_{16} \mathrm{~B}_{12}$ alloy is reported. It is noticeable the near insensibility to the external stress of coercive field and anisotropy field (leading to extremely low value of magnetostriction $1.5 \times 10^{-8}$ ) achieved after the Joule heating by two steps (first one to relax the internal stresses and the second one to develop a fine nanocrystalline structure).

PACS numbers: $75.50 . \mathrm{Kj}, 75.30 . \mathrm{Gw}, 75.80 .+\mathrm{q}$

\section{Introduction}

Amorphous Co-based alloys are generally nearly zero-magnetostrictive materials. This feature implies their use for technological applications as main components of sensors or transducers due to their magnetic properties present normally a high sensitivity to structural defects. These structural defects act like sources of compressive or tensile internal stresses influencing the domain structure and indirectly the magnetization process [1]. For this reason it is possible to improve the soft magnetic properties and the saturation magnetostriction $\left(\lambda_{\mathrm{s}}\right)$ of these alloys by heat treatment, in order to obtain good candidates for technical applications [2].

In this work we present significant results of the effect of the Joule heating on the coercive field $\left(H_{c}\right)$ and $\lambda_{\mathrm{s}}$ in amorphous and nanocrystalline samples of nominal composition $\mathrm{Co}_{66} \mathrm{Fe}_{4} \mathrm{Mo}_{2} \mathrm{Si}_{16} \mathrm{~B}_{12}$ (trademark VITROVAC 6025). Data of $\lambda_{\mathrm{s}}$ in conventional annealed samples are also reported.

\section{Results and discussion}

Ribbon shape samples ( $10 \mathrm{~cm}$ long $5 \mathrm{~mm}$ wide and $20 \mu \mathrm{m}$ thick) of nominal composition $\mathrm{Co}_{66} \mathrm{Fe}_{4} \mathrm{Mo}_{2} \mathrm{Si}_{16} \mathrm{~B}_{12}$ kindly supplied by Vacuumschmelze $\mathrm{GmbH}$, Ger- 
many, were submitted to Joule-heating thermal treatments (intensities of 1.20 and $1.55 \mathrm{~A}$ at different times of duration) which give rise to structural relaxation process $(1.20 \mathrm{~A})$ and the induction of the nanocrystallization process $(1.55 \mathrm{~A})$ as was evidenced by X-ray diffraction and transmission electron microscopy (TEM) studies. Moreover, one sample was submitted to a treatment of two steps $(1.20+1.55 \mathrm{~A}$, the first one is called preannealing). The TEM micrographs of the samples treated at $1.20 \mathrm{~A}$ evidenced absence of crystalline phases, while those of the samples treated at $1.55 \mathrm{~A}$ were of nanocrystalline nature, showing that the microstructure of the samples was formed by nanocrystalline grains of Co $(12 \mathrm{~nm})$ embedded in an amorphous residual matrix.

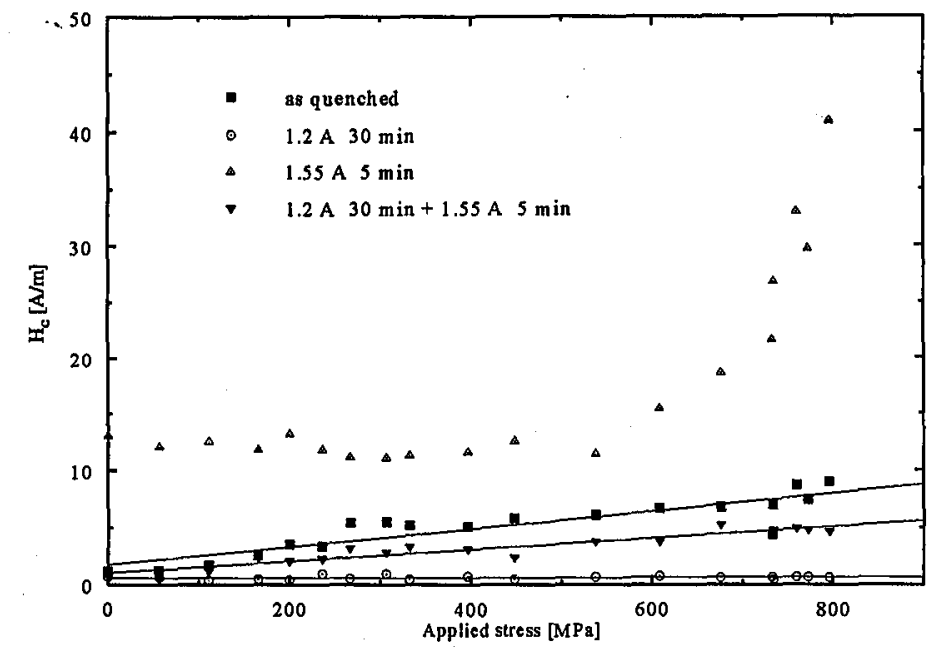

Fig. 1. Variation of the coercive field with the applied tensile stress for the studied samples.

Magnetic measurements under applied tensile stresses in the range 300 to $700 \mathrm{MPa}$ were carried out with a conventional hysteresis loop tracer which allows to evaluate the variation of the coercive field, $H_{\mathrm{c}}$, and saturation magnetostriction constant, $\lambda_{\mathbf{s}}$, with the thermal treatment parameters. The saturation magnetostriction constant was determined using two methods: first one from the stress dependence of the anisotropy field (hysteresis loop) and the second, by using the strain modulated ferromagnetic resonance (SMFMR) technique. It is possible to make comparison between the preannealed sample and other samples which have not been preannealed.

Figure 1 shows the variation of the coercive field for the studied samples with the applied tensile stress. It is possible to observe in Fig. 1 a linear behaviour of the coercive field in all the samples excepting that one treated at $1.55 \mathrm{~A}$ for $5 \mathrm{~min}$. One can also observe a significant reduction of the coercive field values in some of the samples with respect to the as quenched ones. This reduction of the coercive field values (in the sample treated at $1.2 \mathrm{~A} 30 \mathrm{~min}$ ) could be ascribed to the internal stress relaxation such as has been widely reported in metallic glasses [3]: The 


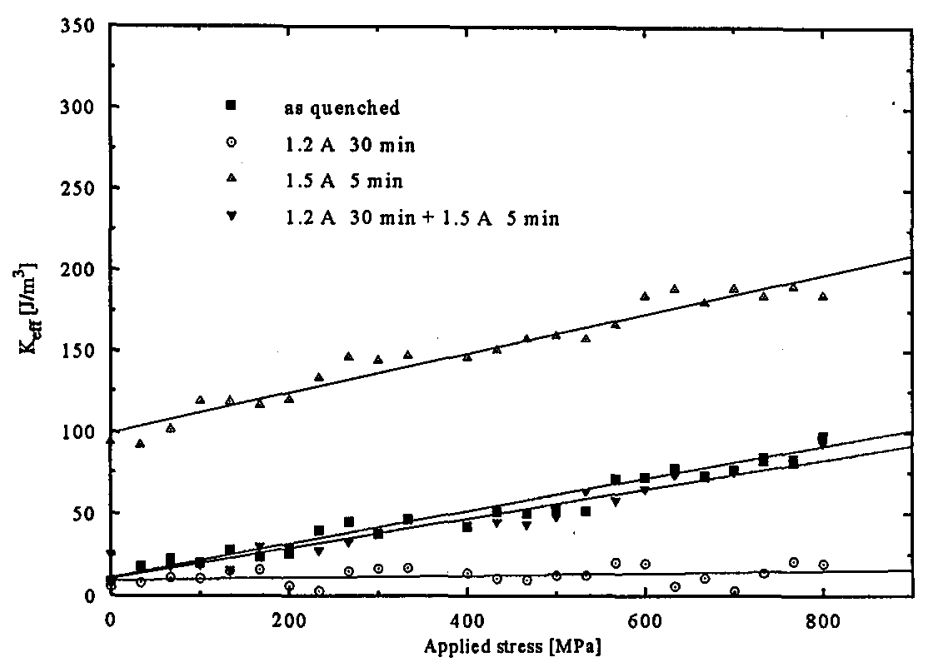

Fig. 2. Variation of the anisotropy field with the applied tensile stress for the studied samples.

increase in the coercive field in the sample treated at $1.55 \mathrm{~A} 5$ min could be related to the hardening connected to a nucleation process before the nanocrystallization process is completed as it has been reported by other authors [4]. Sample treated at $1.20+1.55 \mathrm{~A}$ was nanocrystalline with softening magnetic character owing the magnetic coupling between the small crystallites.

Figure 2 shows the variation of the anisotropy field with the applied tensile stresses for the Joule heated samples. A linear behaviour in all the samples was obtained. One must point out the extreme insensibility of the anisotropy field to the external tensile stress for the preannealed samples $(1.2 \mathrm{~A} 30 \mathrm{~min}+1.55 \mathrm{~A}$ $5 \mathrm{~min}$ and $1.2 \mathrm{~A} 30 \mathrm{~min}$ ), leading to very small values for $\lambda_{\mathrm{s}}$. From these linear dependencies, the saturation magnetostriction constant can be evaluated. Results of $\lambda_{\mathrm{s}}$ are presented in Table $\mathrm{I}$.

In Table II we present results of $\lambda_{\mathrm{s}}$ for furnace annealing samples obtained by the SMFMR technique. As can be seen in this table, no remarkable differences were

TABLE I

Results of the saturation magnetostriction for the Joule heated samples.

\begin{tabular}{l|c}
\hline \hline \multicolumn{1}{c|}{$\begin{array}{c}\text { Annealing temperature } \\
\text { and time }\end{array}$} & $\begin{array}{c}\text { Saturation } \\
\text { magnetostriction }\end{array}$ \\
\hline As quenched & $-0.87 \times 10^{-7}$ \\
1.55 A 5 min & $-2.30 \times 10^{-7}$ \\
1.2 A $30 \mathrm{~min}$ & $-0.39 \times 10^{-7}$ \\
1.2 A $30 \mathrm{~min}+1.55 \mathrm{~A} 5 \mathrm{~min}$ & $-0.15 \times 10^{-7}$
\end{tabular}




\section{TABLE II}

Results of the saturation magnetostriction for the furnace annealed samples.

\begin{tabular}{l|c}
\hline \hline $\begin{array}{c}\text { Annealing temperature } \\
\text { and time }\end{array}$ & $\begin{array}{c}\text { Saturation } \\
\text { magnetostriction }\end{array}$ \\
\hline As quenched & $-0.84 \times 10^{-7}$ \\
$370^{\circ} \mathrm{C} 1 \mathrm{~h}$ & $-0.90 \times 10^{-7}$ \\
$375^{\circ} \mathrm{C} 30 \mathrm{~min}$ & $-0.20 \times 10^{-7}$ \\
$375^{\circ} \mathrm{C} 1 \mathrm{~h}$ & $-0.30 \times 10^{-7}$ \\
$375^{\circ} \mathrm{C} 2 \mathrm{~h}$ & $-0.49 \times 10^{-7}$ \\
$375^{\circ} \mathrm{C} 5 \mathrm{~h}$ & $-0.30 \times 10^{-7}$ \\
$400^{\circ} \mathrm{C} 30 \mathrm{~min}$ & $-0.25 \times 10^{-7}$ \\
$400^{\circ} \mathrm{C} 2 \mathrm{~h}$ & $-0.33 \times 10^{-7}$ \\
$500^{\circ} \mathrm{C} 30 \mathrm{~min}$ & $-2.60 \times 10^{-7}$ \\
$500^{\circ} \mathrm{C} 1 \mathrm{~h}$ & $-1.90 \times 10^{-7}$
\end{tabular}

found in the as quenched values for the two kinds of measurements. Nevertheless, it is possible to obtain lower values for the saturation magnetostriction constant for the Joule heated samples $\left(3.89 \times 10^{-8}\right.$ for the one treated at $\left.1.2 \mathrm{~A} 30 \mathrm{~min}\right)$ than the values obtained in the samples treated by conventional furnace annealing. It is also interesting to realize that the Joule heating technique permits to obtain these low values in a very short interval of time.

\section{Conclusions}

It has been shown that the Joule-heating preannealing effect permits to obtain very low values for the coercivity field and saturation magnetostriction constant in samples of nominal composition $\mathrm{Co}_{66} \mathrm{Fe}_{4} \mathrm{Mo}_{2} \mathrm{Si}_{16} \mathrm{~B}_{12}$. These low values could be ascribed to the internal stress relaxation which permits a better magnetic coupling between the nanocrystallites and also a veraging of the magnetocrystalline anisotropy. The Joule heating has also been proved to be a better technique than the conventional furnace annealing to obtain good candidates for future technological applications (i.e. very low values of the saturation magnetostriction constant) because it is possible to achieve the crystallization temperature of the samples in a very small interval of time.

\section{References}

[1] J. Świerczek, S. Szymura, J. Zbroszczyk, A. Siemko, Physica B 161, 232 (1989).

[2] M. Vázquez, J. González, A. Hernando, J. Magn. Magn. Mater. 53, 323 (1986).

[3] J. González, M. Vázquez, J.M. Barandiarán, A. Hernando, J. Phys. D, Appl. Phys. 21, 162 (1988).

[4] P. Quintana, E. Amano, R. Valenzuela, J.T.S. Irvine, J. Appl. Phys. 75, 6940 (1994). 